\title{
RISK MANAGEMENT AND ITS REFLECTION ON THE QUALITY OF MUNICIPAL SERVICE, CASE STUDY IN SALAHALDDIN SEWERAGE DIRECTORATE
}

\author{
*Husham Muslim Saeed AL-wardi, ** Assist.Prof. Dr. Ayad Taher Mohammed \\ *Researcher, **The supervisor \\ University of Baghdad, College of Administration and Economics, Baghdad, Iraq
}

DOI: $10.37648 / \mathrm{ijrssh} . v 10 \mathrm{i} 03.002$

Received:18 ${ }^{\text {th }}$ May, 2020; Accepted:08 ${ }^{\text {th }}$ June, 2020; Published: $28^{\text {th }}$ June,2020

\begin{abstract}
The current research aims to identify the risk management and its impact on the quality of service in the Salahalddin Sewerage Directorate. This is due to the great impact that the service provided by this institution plays in preserving health and the environment in the community, which has faced many administrative challenges, problems and issues as a result of the rapid and continuous environmental changes, and therefore, the adoption of administrative concepts such as risk management and knowledge of their impact on the quality of the municipal service is necessary to reach this service To the required levels. To achieve the research objectives, two main hypotheses have been formulated, the first of which is to find the extent of the link between the two research variables of risk management and its dimensions (the stage of diagnosing and assessing risks, the stage of decision-making and facing risks, Risk assessment and review stage),And the quality of municipal service by excluding it (tangibility, reliability, response, safety, sympathy), While the second one tries to prove the effect of the first variable on the second variable, The research sample was chosen using the intentional sample method consisting of (65) employees. The questionnaire was used and the number of paragraphs amounted to (43) items to obtain the required data, which were prepared based on two ready-made measures after they were subjected to validity and stability tests,To test the validity of the hypotheses and answer the research questions, an analytical descriptive approach and statistical tests were used, among which were the mean, the standard deviation, the coefficient of variation, and the relative importance, depending on the statistical program (SPSS.V.26), The research reached a set of conclusions, the most important of which is the keenness of Salahalddin Directorate to possess the quality of a municipal service that is provided to all its clients, and employs risk management in order to support that quality, especially through the assessment and review of risks, decision-making and confronting risks as well as diagnosing and assessing risks, Also, the Salahalddin Sewerage Directorate uses risk management to improve the quality of its services from a proactive and defensive perspective, especially when taking decisions to confront them and assessing risk reviews, as well as a correlation and impact of risk management in raising the quality of the service provided.
\end{abstract}

Key words: risk management, municipal service quality. 


\section{INTRODUCTION}

The sewage sector is one of the important sectors at the service level provided by one of the state institutions represented by the Salahalddin Sewer Directorate, one of the sections of the General Sewer Directorate within the formations of the Ministry of Housing, Construction, Municipalities and Public Works, as a result of the great impact that the service provided by this institution plays in preserving health and the environment in Society, which is unable to provide any other institution on the one hand and on the other hand, risk management is an essential component of management in the organizations as it is a systematic method applied across the organization, Which supports the achievement of its goals through the work of a proactive approach in identifying and assessing risks, setting priorities related to them and monitoring them throughout the organization, and since it helps the organization in better preparation for the future and dealing with cases of uncertainty, it cannot be separated from the mechanisms of setting priorities and planning and the risk management approach is based To implement an organizational risk management process, to make this process a shared responsibility of all, and to provide a consistent methodology for its implementation. Risk management helps organizations reduce sudden risks, identify opportunities, and maintain the sustainability of their services, through continuous foresight. Organizational risk management aims to help ensure the sustainability of the organization and enable it to achieve its goals and also requires the adoption of policies and procedures in this regard across the organization, and provides a consistent methodology for its implementationAs the goal is to provide a general paragraph on the subject of the research, its nature and its content, starting with identifying the research variables and the problems based on them and the goal that it seeks to reach in addition to the importance of the research and its spatial and temporal limits.

\section{THE FIRST TOPIC: RESEARCH METHODOLOGY}

This topic deals with the research problem and its importance, in addition to explaining the research objectives and the hypothetical scheme of the nature of the research and its hypotheses, as well as explaining the limits of the research and the methods used in collecting information and explaining the society and sample of the research.

\section{First: The research problem}

There is increasing interest at the present time in reaching a high level of services provided, and achieving the goals for which the organizations were established. Taking into consideration the risks faced by the organizations and by knowing the different types of risks and their effects and limiting them, the best possible amount can be achieved in improving the quality of services, Given that the researcher is a member of Salahalddin Sewer Directorate, it became clear to the limited awareness of the owners of Salahalddin Sewer Directorate of the concept and tasks of risk management and the consequent deficiencies in the process of identifying and managing risks, which reflects negatively on the quality of its services. Different to do the job.

\section{Second: The importance of research}

Public service organizations are increasingly interested in risk management in light of their focus on the quality of municipal service provided, as they are inseparable factors, despite their different intellectual perspectives. As risk management focuses on identifying opportunities as much as it focuses on risk, failure to monitor opportunities to achieve the objectives of the Salahalddin Sewer Directorate is a risk in itself, which calls for an emphasis on risk management practices and the ability to identify and address important risks. The importance of the current research comes in its contribution to providing information and ideas to Salahalddin sewage directorate employees regarding the issue of the impact of risks on the work of the directorate.

\section{Third: Research objectives}

: Research objectives can be illustrated by the following points 
1.Highlighting the theoretical aspects of the researched variables and their dimensions, in addition to preparing a theoretical framework that contributes to increasing the awareness of the research sample for risk management and the quality of municipal service in the Salahalddin Sewerage Directorate, as well as identifying the risk management and its reflection on the quality of the service provided in the directorate in order to achieve the desired goals And to provide the best service to the citizens.

2.Diagnosis of service problems provided in the Salahalddin Sewerage Directorate that are related to risk management and the extent to which these problems can be avoided.

\section{Fourth: Research hypotheses}

In order to reach the objectives of the research and test its hypothesis, the following main hypothesis can be adopted and sub-hypotheses are derived from it as follows:

The main hypothesis: There is a direct correlation relationship with significant significance between the dimensions of risk management (diagnosis and evaluation of risks, decision-making and facing risks, assessment and review of risks) and the quality of municipal service in the Salahalddin Sewerage Directorate and from which the following branches emerge:

1. There is a statistically significant relationship between diagnosis and evaluation of risks and the quality of municipal service.

2. There is a statistically significant statistical relationship between decision-making, facing risks and quality of municipal service.

3. There is a statistically significant relationship between assessing and reviewing risks and the quality of the municipal service.

\section{Fifth: The hypothesis of the research}

Clarifying the dimensions and problem of research and achieving its goals requires building a hypothetical scheme that reflects the nature of the relationships between research variables and the dimensions of the variables and their impact on the organization under research,

And Figure No. (1) shows the hypothesis of the research 


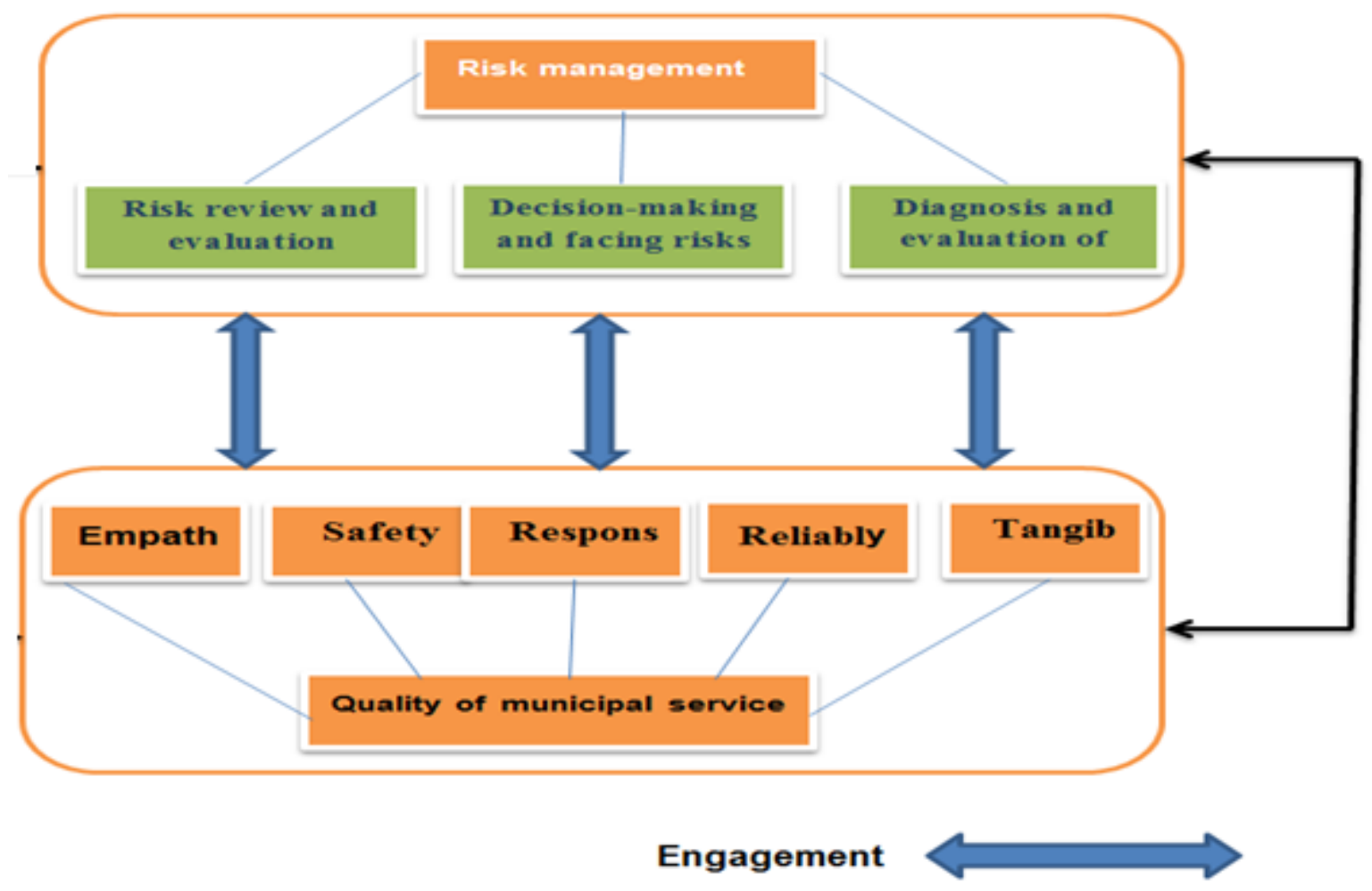

Figure No. 1: The Hypothesis of the Research

Sixth: The study population and sample

The research dealt with risk management and its reflection on the quality of municipal service in the Salahalddin Directorate of Sewerage Society as a research community, and that the research sample consisted of (65) individuals that included the director, assistant director and heads of people, and the relevant employees remained out of the total research community of (91) and those who represented certificates were excluded In preparatory or less, as well as certificates inappropriate for the subject of the research, the researcher distributed to all members of society, after they were comprehensively compiled (the sample is intended).

\section{THE SECOND TOPIC : THEORETICAL SIDE}

First: risk management

\section{The concept of risk management}

It known as a complex phenomenon that contains many physical, monetary, cultural and social dimensions that make risks unforeseen events and unconfirmed possibilities and can affect the goals of the organization at low cost, time or quality (Begum, 2009: 7)

\section{The concept of risk management}

It is known as a systematic and structured method for managing uncertainties That pose a threat, assess risks and devise strategies to mitigate those risks (Suroso \& Fakhrozi, 2018: 203).

\section{The importance of risk management}

the importance of risk management is embodied in (Hammad, 2007: 223):

a.a. Developing methods of decision-making, planning and setting priorities through a comprehensive and organized awareness of the organization's activities.

B. It also helps in making decisions in the various departments of the organization 
c. Highlighting the positive and negative gaps and opportunities available for projects to avoid future losses in addition to being a tool for implementing the strategy, as it provides the organization with a better view of the future.

d. It also measures the organization's capital adequacy and ability to meet its obligations, not to fall into the risk of a lack of liquidity.

\section{Objectives of risk management}

Risk management has goals represented in (AlHussaini, 2007: 47)

a. Provide a framework for the organization to support the implementation of future activities in a coordinated and controlled manner while maximizing the operational efficiency of all departments of the organization.

b. Likewise, reducing non-essential changes in organizational activities to prevent these activities from being exposed to risks and protecting and developing the organization's resources and assets necessary to carry out various activities.

c. Developing decision-making methods and identifying priorities through a comprehensive awareness of the opportunities, risks and changes facing the organization's activities.

\section{Dimensions of risk}

Dimensions of risks can be formulated based on a study (Abu Hajeer, 2014)

a. The stage of diagnosis and evaluation of risks:This stage includes trying to forecast potential risks and describing them with clarifying their effects to prepare for them, through reports that clarify this, and organizing workshops to explore potential risks and determining the probability of occurrence and degree of risk, carrying out studies and procedures that enable us to diagnose risks and work to anticipate their outcomes if they occur and the size of the loss with Preparing reports on it and submitting them to the concerned authorities
B. Decision-making stage and facing risks: At this stage, a decision is made with one of the possibilities either (taking risks, diversifying risks, avoiding risks and reducing their effects, transferring risks). An accurate analysis and description of the risks is done, and we explore their impact on jobs and activities in addition to developing a strategy and policy for risk management, and here the appropriate decision is taken in the face of Risks.

C. The risk assessment and review stage:Through this stage, the procedures followed and information has been verified, has given the planned results, and whether they were appropriate in collecting risks, and reports are prepared clarifying the risk of the remaining deviations, and also carrying out an evaluation and review of risk management steps and identifying lessons learned to examine risk management in the future and work on the cognitive development of assistance To make better decisions to confront the risks, with the relevant parties aware of the final report

\section{Second: The quality of service}

\section{The concept of service}

The percentage of employment in services in Britain and Australia reaches more than $70 \%$, while we see that this percentage in Canada reaches $73 \%$, while in the United States the proportion of the workforce in services is more than $72 \%$ of the total workforce is superior This is true of all other economic sectors (Ashour and El-Abadleh, 2007, 102).

\section{Quality of municipal services.}

The quality of municipal services does not differ from the quality of service in general. Municipal services are no longer traditional tasks and tasks that municipal departments take upon themselves to undertake, but rather have become a prominent feature of the era that aims to achieve prosperity and progress for humanity (Al-Khatib, 2012, 187).

\section{Service characteristics}

The service is unique in a set of characteristics when compared to the commodity, as follows: 
a. Intangibility: That is, the service does not have a physical presence. If satisfying the need and satisfying its requirements is carried out in a greater form through intangible things, then what the consumer buys is the service, but if the opposite is the case, the means of gratification in this case will be a commodity (Hussein, 2010: 44- 45).

B. Heterogeneity: Services are characterized in this capacity, which means the inability to stereotypes the service, especially those that depend heavily on people, so it is difficult for service providers to pledge their services to be identical and homogeneous each time the service is provided (Azzam and others, 2009: 296).

C. Thalassemia: Thalassemia means the production and consumption process which means that the service cannot be separated from the commodity that is being sold, and is consumed at the same time, and it depends on its provision on personal contact between the service provider and the customer (Mokhlis, 2011: 125).

D.Fading: That is, the service cannot be stored or kept for a period of time, and it does not exceed the time of demand for it, especially if the request is unstable for the services that individuals require (Kotler, 2003: 258).

e. Non-ownership: The lack of transfer of ownership is a quality that distinguishes the commodity from the service, because the customer can use the service for a certain period without owning it, unlike the commodity that gives the customer the right to own it as in physical goods (Mandil, 2002: 270-271).

\section{Quality of service}

Quality of service and its understanding today is necessary for the success of any organization by satisfying the needs and desires of its customers, as the differentiation of organizations in providing them enhances the status and achievement of its goals, as quality of service and customer satisfaction and maintaining long-term relationships with them has become a fundamental issue for the survival of successful organizations (Adem \& Devi, 2015: 73).

\section{Quality service dimensions}

1.Tangibility: Tangibility refers to being an expression of the material capabilities, equipment (tools) used, human resources and communication equipment that can be seen as a basis for service provision (Bakri, 2011: 296)

2.Reliability: Reliability refers to the ability to perform services with reliability, conformity and high accuracy (Stevenson, 2005: 387).

3.Response: means the willingness and willingness of the service provider to provide assistance to the customer, or solve its specific problems, such as if the accountant is willing and ready to meet a customer who has an urgent problem that requires his assistance and intervention to solve it? (Al-Taie and Al-Alaq, 2009: 245).

4.Safety: This dimension plays a large and effective role in attracting customers to request the service, because providing the element of safety and trust is a key point for the beneficiary and represents one of the basic needs that he is looking for in the service (AlSumaidaie and Youssef, 2010: 93).

5.Empathy: Empathy refers to the availability of the qualities of fitness and discipline in the person of the service provider, as well as courteousness, affection and friendship with customers, in order to build good relations with them that are respectful and easy to communicate and care for them (Fadila, 2010: 30).

\section{THE THIRD TOPIC : PRACTICAL SIDE}

First: the results of descriptive analysis and the arrangement of the dimensions of the two variables according to the coefficient of relative difference.

1.The results of the descriptive analysis and the order of the dimensions of risk management according to the relative difference coefficient as shown in Table (1). 
Table (1) the results of descriptive analysis and the dimensions of risk management according to the relative difference coefficient

\begin{tabular}{|c|c|c|c|c|}
\hline $\begin{array}{l}\text { Relative } \\
\text { importance }\end{array}$ & $\begin{array}{l}\text { Coefficient of } \\
\text { variation }\end{array}$ & standard deviation & $\begin{array}{l}\text { Arithmetic } \\
\text { mean }\end{array}$ & Variables \\
\hline$\underline{78.6 \%}$ & $14.7 \%$ & $\underline{0.579}$ & $\underline{3.93}$ & $\begin{array}{l}\text { Diagnosis and evaluation } \\
\text { of risks }\end{array}$ \\
\hline$\underline{79.2 \%}$ & $\underline{14.1 \%}$ & $\underline{0.558}$ & $\underline{3.96}$ & $\begin{array}{l}\text { Decision-making and } \\
\text { facing risks }\end{array}$ \\
\hline$\underline{78.4 \%}$ & $\underline{16.2 \%}$ & $\underline{0.636}$ & $\underline{3.92}$ & $\begin{array}{l}\text { Risk assessment and } \\
\text { review }\end{array}$ \\
\hline $78.8 \%$ & $13.6 \%$ & 0.534 & 3.94 & Risk Management \\
\hline
\end{tabular}

2.The results of the descriptive analysis and the arrangement of the dimensions of the municipal service quality according to the relative difference coefficient, as shown in Table (2).

Table (2) the results of descriptive analysis and the dimensions of the quality of municipal services according to the coefficient of relative difference.

\begin{tabular}{|l|l|l|l|l|}
\hline Relative weight & $\begin{array}{l}\text { Coefficient of } \\
\text { variation }\end{array}$ & $\begin{array}{l}\text { standard } \\
\text { deviation }\end{array}$ & Arithmetic mean & Variables \\
\hline$\underline{\mathbf{7 9 . 6 \%}}$ & $\underline{15.3 \%}$ & $\underline{\mathbf{0 . 6 0 8}}$ & $\underline{\mathbf{3 . 9 8}}$ & Tangibility \\
\hline$\underline{\mathbf{8 1 . 2 \%}}$ & $\underline{\mathbf{1 2 . 5 \%}}$ & $\underline{\mathbf{0 . 5 1 0}}$ & $\underline{\mathbf{4 . 0 6}}$ & Reliability \\
\hline$\underline{\mathbf{8 1 . 6 \%}}$ & $\underline{\mathbf{1 4 . 2 \%}}$ & $\underline{\mathbf{0 . 5 7 8}}$ & $\underline{\mathbf{4 . 0 8}}$ & The response \\
\hline$\underline{\mathbf{8 2 . 2 \%}}$ & $\underline{\mathbf{1 2 . 5 \%}}$ & $\underline{\mathbf{0 . 5 1 4}}$ & $\underline{\mathbf{4 . 1 1}}$ & Safety \\
\hline$\underline{\mathbf{8 0 \%}}$ & $\underline{\mathbf{1 5 . 8 \%}}$ & $\underline{\mathbf{0 . 6 3 5}}$ & $\underline{\mathbf{4 . 0 0}}$ & Empathy \\
\hline $\mathbf{8 1 \%}$ & $\mathbf{1 1 . 6 \%}$ & $\mathbf{0 . 4 7 1}$ & $\mathbf{4 . 0 5}$ & $\begin{array}{l}\text { Quality of } \\
\text { municipal service }\end{array}$ \\
\hline
\end{tabular}

\section{Second :To check the link hypothesis}

The researcher set out in his test of the validity of the main hypothesis (risk management in the quality of municipal services is directly related to morale) and the following sub-hypotheses have emerged:

a.Diagnosis and evaluation of risks is related to the quality of municipal services and their dimensions are morally direct.

b.Decision-making and risk-taking are linked to the quality of municipal services and their dimensions are morally direct.

c. The risk assessment and review are related to the quality of the municipal service and its moral and direct dimensions.
Verification of the first sub-hypothesis: Through the researcher's briefing on the results of Table (1), he found that the stage of diagnosing and evaluating risks has achieved three relationships out of six, at a rate of $(50 \%)$ of the relationships, all of which are under a level of significance less than $(5 \%)$ and were as following:

A- Positive correlation relationship positive $(0.394 * *)$ with reliability at level of significance $(0.003)$.

B - positive correlation positive correlation $(0.300 *)$ with response under significant level (0.026).

C- A positive correlative correlation $(0.271 *)$ with quality of service under a significant level (0.045). 
$\mathrm{d}$ - While there was no correlation between the stage of diagnosis and evaluation of risks with tangibility, safety, and sympathy because the test morale was greater than the level of significance (0.05).

From all of the above, the first sub-hypothesis from the first main hypothesis is accepted at the macro level and partly at the dimension level.

Verification of the second sub-hypothesis: By informing the researcher of the results of Table (3), he found that the decision-making stage and facing the risks have achieved six relationships out of six, and at a rate of $(100 \%)$ of the relationships, all of which are under a moral level of less than (5\%), and they were on As follows:

A- Positivecorrelative correlation relationship (0.497 **) with the quality of municipal service at the level of significance (0.000).

B- Positivecorrelative correlationrelationship (0.464 **) with dependency below level (0.000).

C- A positive correlative correlationrelationship ( 0.418

**) with sympathy below a significant level (0.001)

D- Positivecorrelative correlationrelationship (0.416

**) with response under significant level (0.002).

E- A positive correlative correlationrelationship $(0.410$

**) with safety below the significant level (0.002).

F- positive correlative correlationrelationship (0.359

**) with tangibility under significant level (0.007).

From all the above, the second sub-hypothesis from the first main hypothesis is accepted.

Verification of the third sub-hypothesis: The researcher showed from the results of Table (3) the achievement of the risk assessment and review stage five correlations out of six, with a ratio of $(83.33 \%)$ of the relationships, all of which are under a level of significance less than (5\%), and they were as follows:

A- Positive correlative correlation relationship $(0.576$ $* *)$ with tangibility at the level of significance (0.000).
B- Positive correlative correlation relationship $(0.540$ **) with dependency below level (0.000).

C- Positive correlative correlation relationship $(0.525$ **) with response under a significant level (0.000).

D- Positive correlative correlation relationship (0.524 **) with the quality of municipal service under a significant level (0.002).

E- A Positive correlative correlation relationship $(0.275 *)$ with sympathy below a significant level (0.042).

F- There is no significant correlation relationship with safety, as the test significance was $(0.061)$ and it is greater than the level of significance (0.05).

From all the above, the second sub-hypothesis from the first main hypothesis is accepted

Verification of the first main hypothesis: With the return of the researcher to the results of Table (3), the main independent variable found risk management had achieved six relationships out of six, and by (100\%) of the relationships, all of them under a level of significance less than $(5 \%)$ was as follows:

A- Positive correlative correlation relationship $(0.518$ **) with reliability at the level of significance $(0.000)$.

B - Positive correlative correlation relationship (0.479 **) with the quality of municipal service under the level of morale (0.000).

C- Positive correlative correlation relationship (0.461

**) with response under a significant level (0.000).

D- Positive correlative correlation relationship $(0.438$

**) with tangibility under significant level (0.001).

C- Positive correlative correlation relationship (0.295

*) with sympathy below a significant level (0.029).

H - Positive correlative correlation relationship (0.281

*) with safety below the level of significance (0.038). 
Table (3) the search variables correlation matrix

\begin{tabular}{|c|c|c|c|c|c|c|}
\hline $\begin{array}{l}\text { Quality of } \\
\text { municipal } \\
\text { service }\end{array}$ & Empathy & Safety & $\begin{array}{l}\text { The } \\
\text { response }\end{array}$ & Reliability & tangibility & \\
\hline 0.271 : & 0.111 & 0.102 & $0.300 *$ & $0.394^{*} *$ & 0.233 & \multirow{3}{*}{$\begin{array}{c}\text { Diagnosis } \\
\text { and evaluation } \\
\text { of risks }\end{array}$} \\
\hline 0.045 & 0.418 & 0.461 & 0.026 & 0.003 & 0.086 & \\
\hline 55 & 55 & 55 & 55 & 55 & 55 & \\
\hline $0.497 *$ & $0.418 * \approx$ & $0.410 *$ & $0.416 \%$ & $0.464 * \approx$ & $0.359 * *$ & \multirow{3}{*}{$\begin{array}{l}\text { Decision- } \\
\text { making and } \\
\text { facing risks }\end{array}$} \\
\hline 0.000 & 0.001 & 0.002 & 0.002 & 0.000 & 0.007 & \\
\hline 55 & 55 & 55 & 55 & 55 & 55 & \\
\hline $0.524 * *$ & 0.275 & 0.255 & $0.525 \%$ & $0.540 \approx$ & $0.576 \%$ & \multirow{3}{*}{$\begin{array}{l}\text { Risk } \\
\text { assessment } \\
\text { and review }\end{array}$} \\
\hline 0.000 & 0.042 & 0.061 & 0.000 & 0.000 & 0.000 & \\
\hline 55 & 55 & 55 & 55 & 55 & 55 & \\
\hline $0.479 \approx$ & $0.295 \%$ & $0.281 \%$ & $0.461 \%$ & $0.518 \approx$ & $\mathbf{0 . 4 3 8} \approx *$ & \multirow{3}{*}{$\begin{array}{c}\text { Risk } \\
\text { Management }\end{array}$} \\
\hline 0.000 & 0.029 & 0.038 & 0.002 & 0.000 & 0.001 & \\
\hline 55 & 55 & 55 & 55 & 55 & 55 & \\
\hline
\end{tabular}

$P * \approx 0.01, P \approx<0.05$

\section{THE FOURTH TOPIC : CONCLUSIONS AND RECOMMENDATIONS}

\section{First: Conclusions}

1.The Salahalddin Sewerage Directorate adopts to respond to the needs and desires of its customers and reinforces it with its desire to achieve without regard to its burdens and preoccupation with its internal tasks.

2.The Salahalddin Sewerage Directorate has a noticeable interest in providing safety in the light of its behavior, which gives the impression of its customers with confidence and satisfaction, as well as their personal honesty when dealing with their customers.

3.The Salahalddin Sewerage Directorate possesses the ability to sympathize with its customers by showing feelings of affection and respect without looking at their job and social and job backgrounds as well as providing the service to everyone at any time without delay or neglect.

4.The Salahalddin Sewerage Directorate is keen to possess the quality of a municipal service that it provides to all its clients, and employs risk management in order to enhance that quality, especially through the assessment and review of risks, decision-making and facing risks as well as diagnosing and assessing risks.

5.The Salahalddin Sewerage Directorate uses risk management to improve the quality of its services from a proactive and defensive perspective, especially when it makes decisions to confront them and assess the risk review. 


\section{Second: Recommendations}

1.The Salahalddin Sewerage Directorate should respond quickly to citizens 'requests about the service provided, in particular by informing them of the time to fulfill their requests and adhering to it, as well as periodically distributing their burdens to teams, and working on early preparedness to face risks and challenges by distributing periodic statistics to departments that can: During the course of drawing up the necessary plans to respond to all the needs and requests of citizens.

2.The necessity of Salahalddin Sewerage Directorate's interest in providing safety for the services it provides by exercising personal trust and respect for citizens, receiving their requests and complaints and looking at them as suffering more than they are complaints to spread reassurance and sow confidence and comfort in them.

3.The Salahalddin Sewerage Directorate should pay attention to sympathy, given that it provides a service to citizens and provides its services at any time to everyone in a fair manner without delay, delay or neglect, and to ensure that they are met accurately in light of the available capabilities and resources, in addition to showing kindness, courtesy and persuasion by finding a specialized unit to receive Complaints and suggestions and linked to all units and departments of the Directorate.

4. Salahalddin Directorate should enhance its interest in risk management, especially the assessment and review of risks and decision-making to face risks, as it is the best way to improve the quality of its services.

5.The necessity of the Salahalddin Sewerage Directorate to continuously improve the level of its services, especially when it pays attention in managing the risks it faces by finding a specialized unit that means analysis and diagnosing risks and providing the necessary information to the decision maker according to the available alternatives, and then constantly reviewing and evaluating each alternative and evaluating it.

\section{SOURCES:}

3. Begum Ongel,(2009),"Assessing Risk Management Maturity: Framework for the Construction Companies", Master Thesis in building Science in Architecture department, Middle East Technical University.

6. Suroso , Jarot \& Fakhrozi , Muhammad ( 2018 ), " Assessment of Information system Risk Management with Octave Allegro Alsevier Ltd " Voi ( 135 ) pp ( $202-213$ ).

7.Hammad, Tariq Abdel Aal (2007), "Risk Management, Credit, Investment, Derivative and Exchange Rate Risk", University House, Alexandria.

8. Al-Husseini, Rakia Jawad Naji (2007), "Designing and building a risk management information system in industrial companies - An applied study at the Al Furat State Chemical Industries Company in Hilla", unpublished Master Thesis, Technical College, Hilla, Iraq

10.43. Ashour, Youssef Hussein, and Al-Abadleh, Talal Othman, (2007), Measuring the Quality of Educational Services in Graduate Studies, The Case of an MBA Program at the Islamic University of Gaza, Al-Aqsa University Journal, 11th Journal, First Issue.

11. Al-Khatib, Majed Matar Abdul Karim, (2012), Standards for Land Use and its Impairment on Municipal Services: Al-Aziziya City and Municipality as a Model, Al-Mustansiriya Journal for Arab and International Studies, No. (42)

13. Hussein, Intisar Aziz, (2010) "The Impact of Strategic Analysis on Quality of Service." An Exploratory Study of Managers' Views on a Sample of Iraqi Banks, Master Thesis in Business Administration, Al-Mustansiriya University. 
14. Azzam, Abdul Basit Hassouna and Zakaria, Ahmed and Mustafa, Saeed Al-Sheikh (2009), "Principles of Modern Marketing between Theory and Practice", second edition, Dar Al-Masirah for Publishing and Distribution, Amman.

15. Mokhlis, S., Aleesa, Y., \& Mamat, I. (2011). Municipal service quality and citizen satisfaction in southern Thailand. Journal of Public Administration and Governance, 1(1), 122-137.

16. Kotler, Philip (2003), marketing management, prentice hall international Inc.

17. Mandil, Abdul-Jabbar (2002), "The Basics of Modern Marketing", Dar Al-Alamiya International and Dar AlThaqafa for Publishing and Distribution, Amman, Jordan

18. Adem, Ubah \&Devi, M. Sarada ,(2015)," A Study on Services Quality of Commercial Banks in Dire Dawa,Ethiopia: A Comparative Study of Public and Private Banks, European Journal of Business and Management, Vol.7, No.28.

20.Al-Bakri, Thamer Yasser (2011), "Marketing Management", 4th edition, Ithraa for Publishing and Distribution, Amman

21. Stevenson ,William J.(2005),” Operations Management “, 8th.ed McGraw ,Hill, New York.

22.Al-Taei, Hamid Abdul Nabi and Al-Alaq, Bashir (2009) "Marketing Services", a strategic, functional, and applied approach to entry ", 1st floor, Dar Al-Yazouri Publishing and Distribution, Amman.

23.Al-Sumaidaie, Mahmoud and Youssef, Rudeina (2010) "Marketing Services", 1st Floor, Al Masirah House for Publishing and Distribution - Amman

24. Fadela, Sherov (2010) "The effect of electronic marketing on the quality of banking services", a case study of some banks in Algeria, Master Thesis, Faculty of Economic Sciences, University of Mentouri, Algeria.

25. Abu Hajeer, Tariq Mufleh Jumaa (2014), "Strategic leadership and its role in risk and crisis management" - an applied study on Palestinian government institutions, thesis submitted for a PhD degree in business administration, faculty of commerce, Suez Canal University. 